\title{
Analysis on Construction Technology of Reinforced Concrete Tied Arch Bridge
}

\author{
Zhongyu Wang* \\ China Merchants Chongqing Communications Technology Research \& Design Institute CO., LTD. Chongqing 400067, China \\ *Corresponding author: Zhongyu Wang, ccrdiyu@gmail.com

\begin{abstract}
Bridge construction has received a lot of attention as transportation continues to improve. Reinforced concrete linked arch bridges are a common bridge style in today's bridge construction. This type of bridge not only has a basic and generous shape, but it is also incredibly easy to construct, resulting in significant material and construction cost savings. This article analyzes the construction technology of a reinforced concrete linked arch bridge in order to achieve good construction and application. It is hoped that this analysis can provide a scientific reference for the guarantee of the construction quality and subsequent application effect of this kind of bridge.
\end{abstract}

Keywords: Reinforced concrete; Tied arch bridge; Construction technology

Publication date: November 2021; Online publication: November 30, 2021

\section{Introduction}

The proper application of construction technology during the construction of a tied arch bridge made of reinforced concrete is critical to ensuring the overall arch bridge's construction quality and safety. As a result, during the construction process, the construction unit must have a thorough understanding of its primary construction methods and be able to apply the appropriate construction technology to the real project. This approach, we can effectively secure the reinforced concrete tied arch bridge's construction effect and establish a firm foundation for its subsequent good application.

\section{Analysis on the main construction methods of reinforced concrete tied arch bridge}

During the construction of tied arch bridge in the form of reinforced concrete, there are two main construction schemes. The first is to set up scheduled installation, and the second is to cast the support insitu. In the specific construction, the construction unit shall realize the reasonable selection of construction scheme according to the comprehensive consideration of the landform of the construction site, surrounding environment, actual construction conditions and construction cost ${ }^{[1-3]}$. The following is the comparison of the two construction schemes (Table 1.)

\section{Analysis on the construction technology key point of reinforced concrete tied arch bridge}

This study is the construction of reinforced concrete tied arch bridge in a highway crossing section of a high-speed railway. The type of tied arch bridge is 1-96m structure. The cast-in-place pile is used as the foundation, the bearing platform is in the form of double-layer, and the pier is T-shaped. The tie beam is arranged through an integral box girder. The total length of the beam is $100 \mathrm{~m}$, the calculated span is $96 \mathrm{~m}$, the arch rib is catenary, and its plane height is $19.2 \mathrm{~m}$. In the specific construction, through the comprehensive consideration of various factors, it is finally decided to adopt the method of cast-in-place support for construction, and the construction scheme of beam first and arch second is formulated. During 
the construction, the cast-in-situ construction is mainly carried out through the full framing in the form of bowl buckle. The arch crown and end beam support at the top of the same main pier are constructed at the same time with the formwork. The arch seat and end beam on the same arch crown are poured by one-time pouring. The construction of tie bar and middle cross beam shall be carried out at the same time, and shall be erected as a whole. Tie bar pouring is carried out in two sections, and the sequence of arch assist pouring is from arch seat to arch crown. During the construction, the concrete pouring shall be carried out in strict accordance with the design steps. The concrete on the pouring surface is mainly transported by automobile pump. After pouring, the tie bar and working support will be connected into an integral structure. The following is the analysis of the main construction technologies during the construction of reinforced concrete tie arch bridge.

Table 1. Comparison of two main schemes in the construction of reinforced concrete tied arch bridge

\begin{tabular}{|c|c|c|c|}
\hline Number & Project & $\begin{array}{l}\text { Setting up scheduled } \\
\text { installation }\end{array}$ & Casting the support in situ \\
\hline 1 & $\begin{array}{l}\text { Support } \\
\text { installation } \\
\text { requirements }\end{array}$ & Not high & Very high \\
\hline 2 & $\begin{array}{l}\text { Matters } \\
\text { needing } \\
\text { attention }\end{array}$ & $\begin{array}{l}\text { After the support at the wet joint } \\
\text { position is erected and stressed, } \\
\text { the support height can be } \\
\text { adjusted with the help of Jack, } \\
\text { and the wet joint pouring can be } \\
\text { carried out only after the height } \\
\text { is adjusted to the design } \\
\text { requirements }\end{array}$ & $\begin{array}{l}\text { It is necessary to ensure that the support } \\
\text { basically does not precipitate under the } \\
\text { condition of bearing flow concrete, and it } \\
\text { shall comply with relevant regulations in } \\
\text { construction }{ }^{[5]} \text {. Therefore, in the process of } \\
\text { designing this kind of support, we must } \\
\text { comprehensively analyze the concrete } \\
\text { weight of arch and the actual construction } \\
\text { load. }\end{array}$ \\
\hline
\end{tabular}

\subsection{Reinforcement construction technology}

Because the construction cushion cap of reinforced concrete tied arch bridge has a large volume and there is a large amount of reinforcement in construction, most reinforcement needs to be processed in the processing yard and then transported to the construction site for direct installation, and the reinforcement fabrication and installation of each layer need to be completed at one time. Based on this, in the specific construction, the construction unit must reasonably apply the reinforcement construction technology. Firstly, the quality of reinforcement shall be controlled. All reinforcement shall be subject to quality acceptance before mobilization, and can be put into use only when the model and quality are fully consistent with the actual engineering standards. Secondly, during the loading and unloading of reinforcement, it is not allowed to throw it from a high place. Thirdly, when processing the reinforcement, it must be processed in strict accordance with the design drawings, especially when binding the reinforcement, the floor must be padded with square wood to prevent the plate surface from being scratched when the reinforcement is dragged. At the same time, the high-strength concrete cushion block shall be set between the reinforcement and the formwork to ensure the thickness of the reinforcement protective layer ${ }^{[6]}$. Finally, in the process of welding the reinforcement, isolation treatment must be done through the liner to avoid burning the plate surface by welding slag. 


\subsection{Support installation and construction technology}

Before arranging the support, it is necessary to make a detailed stress calculation for each part of the whole reinforced concrete tied arch bridge, and take this as the basis to reasonably determine the safe layout distance of the support. In order to ensure the stress safety, the spacing between supports must be set reasonably with the specific stress changes of each part. During the specific erection of the support, the construction unit must control it in strict accordance with the designed support layout. In this process, it is necessary to ensure that the support design is consistent with the actual weight of concrete and the load requirements in specific construction. Especially for the support at the arch rib, the node support must be selected during installation, and the transverse and longitudinal connections need to be added between the supports. Only in this way can we effectively ensure the quality of support installation and construction and meet the quality and safety requirements of the whole project.

\subsection{Arch foot construction technology}

In the process of the arch foot construction of reinforced concrete tied arch bridge, the solid section shall be set within $8 \mathrm{~m}$ in the general direction. If the width in the transverse direction is more than $17 \mathrm{~m}$, the corresponding transition section or chamfer shall be set at the gradual change position of its cross section. During the construction of arch foot, the concrete cast-in-situ can be carried out in two sections. Before the pouring construction, it is necessary to install these materials such as arch rib reinforcement, and then carry out the first concrete pouring. After the completion of phase II dead load construction, the second concrete pouring construction can be carried out. In this process, the reinforcement must be properly positioned, so as to effectively avoid the displacement of reinforcement during concrete pouring, so as to effectively control the position deviation of arch rib reinforcement and provide a good guarantee for construction quality and safety ${ }^{[7]}$.

\subsection{Cast in situ construction technology of soil beam}

During the specific construction, the pouring and forming of arch seat and end beam shall be realized at one time, and each tie rod shall be poured according to both ends. Among them, the cast-in-situ construction of concrete shall be carried out in a horizontal layered manner. The concrete at the arch seat and the end beam shall be poured at the same time, and the concrete shall be pushed forward through the inclined plane layer by layer until it is poured to the top of the end beam. When the concrete is about to set initially, the remaining concrete shall be poured in layers ${ }^{[8]}$. In this process, the construction unit should arrange a special person in charge to track and inspect the actual situation of the support and template. If there is a normal situation, the concrete pouring construction should be stopped immediately. After the normal situation is found out and treated, the concrete pouring can be continued.

\subsection{Arch rib installation and construction technology}

During the installation and construction of the arch rib of this kind of arch bridge, its section is usually set in the form of dumbbell concrete-filled steel tube. After the tie bar tensioning is completed, the arch rib can be installed. In this process, it is necessary to pre-assemble the arch rib. During the construction, it is necessary to fix the edge section of the arch rib on the bed-jig to keep its positioning accurate. For each assembly stage, it is necessary to make corresponding assembly marks, so as to provide sufficient reference for the subsequent on-site docking and installation construction. In the arch assist section, both sides of the tie rod need to be supported with round logs, and the camber should be reserved according to the actual situation, so as to ensure the accuracy of construction. For the wooden square at the top of the support, it should be copied through the wooden wedge, and then the elevation at the bottom of the support should be detected by the level ${ }^{[9]}$. The fabrication and assembly of arch ribs can be carried out only after the above 
work is completed and qualified. In this process, the construction unit must be in strict accordance with the actual design requirements to do a good job of opening the lifting point hole. At the same time, it should do a good job of the installation of the attached frame, and do a good job of opening cover plate number and storage. After the concrete pouring construction is completed, the hole cover can be covered and welded firmly.

\subsection{Construction technology of concrete pouring in arch}

After completing the construction of prestressed steel cable, the construction unit needs to check and reinforce the support, properly connect the vertical rod on both sides of the tie rod, and set the arch support to the top of the tie rod, and then the arch support can be used for concrete pouring construction. The arch support is usually erected with steel pipe in the form of bowl buckle. With the help of single arch support concrete, it is poured symmetrically from the arch seat to the arch crown until it is formed ${ }^{[10]}$. After pouring and forming, it is necessary to carry out quality inspection with the help of ultrasonic inspection technology. If a void is found during the test, it needs to be treated by drilling and grouting technology.

\section{Conclusion}

To sum up, in the process of construction of reinforced concrete tied arch bridge, only by controlling its construction technology can the construction quality be effectively ensured. Therefore, in the specific construction process, the construction unit must reasonably formulate its construction scheme in strict accordance with the actual situation and combined with the actual needs, and reasonably apply the corresponding construction technology to the actual construction, including reinforcement construction technology, support installation construction technology, arch foot construction technology, soil beam castin-place construction technology, arch rib installation construction technology and arch concrete pouring construction technology, etc. In this way, the corresponding construction technology can give full play to the technical advantages in the construction of reinforced concrete tied arch bridge, meet the construction requirements of the actual project, ensure the overall project quality, and provide good quality and safety guarantee for the subsequent application of this kind of arch bridge

\section{Disclosure statement}

The author declares no conflict of interest.

\section{References}

[1] Zhong S, 2021, Research on Construction Monitoring and Key Technology of Long-span Reinforced Concrete Tie Arch Bridge.Tutor: Feng Z, Chen Y. Lanzhou Jiaotong University.

[2] Yu L, Yang J, 2020, Research on Construction Technology of Reinforced Concrete Side Arch Rib. Intelligent City, (09): 188-189.

[3] Jin C, 2020, Research on Construction Technology of Long Span Concrete Filled Steel Tubular Tie Arch Bridge. Engineering and Technological Research, (03): 99-100.

[4] Che X, 2019, Research on Reasonable Bridge Formation and Cable Force Optimization of Reinforced Concrete Tie Arch Bridge. Tutor: Du B. Guizhou University.

[5] Yu Y, 2019, Dynamic Characteristics of Steel Box Tie Arch Bridge and Its Stability Analysis during Construction process. Tutor: Sun H, Qu G. Shenyang University of Technology.

[6] Xing Y, 2019, Research on Key Problems of Design and Construction of Concrete Filled Steel Tube Simply Supported Arch Bridge. Tutor: Zhang C, Wang X. Tsinghua University.

[7] Chen X, 2019, Analysis of Cable Force and Stability of Concrete-filled Steel Tubular Tie Arch Bridge. 
Tutor: Ning X. Kunming University of Science and Technology.

[8] Wu W, 2019, Research on the Application of BIM technology in Design and Construction of Underpass Tie Arch Bridge. Tutor: Cheng Y. Lanzhou Jiaotong University.

[9] Bian C, 2018, Analysis of the Influence of Transverse Brace Arrangement on Seismic Response and Wind Load of Tie Arch Bridge. Tutor: Zhao Qing. Anhui Jianzhu University.

[10] Qiao Y, 2018, Study on Construction Control of 64M Simply-supported Pole-arch Bridge of Yinxi Railway. Tutor: Ji W, Cao G. Lanzhou Jiaotong University. 